\title{
Differences and similarities in the intra-uterine behaviour of monozygotic and dizygotic twins
}

\author{
Alessandra Piontelli, Luisa Bocconi, Chiara Boschetto, Alessandra Kustermann and Umberto Nicolini \\ Division of Maternal-Foetal Medicine, 1st Department of Obstetrics and Gynaecology, University of Milan, Italy
}

\begin{abstract}
Diagnostic advances have made it possible to use ultrasonograph to assess placentation and therefore zygosity in utero in the case of monochorionic-monozygotic twins. Foetal behaviour of 15 monozygotic and 15 unlike-sexed dizygotic twin pairs was studied serially with ultrasounds from 10 to 22 weeks gestational age. Each twin, regardless of its zygosity, showed individualised behavioural styles. One twin was found to be 'dominant' in the sense of being more active, but less reactive, possibly due to the fewer stimuli being generated by its co-twin. Monozygotic twins, as opposed to dizygotic twins, showed greater similarities in activity and reactivity levels, but were never behaviourally identical and decreased in likeness with increasing age. Our data suggest that so-called identical twins are very similar, but not behaviourally identical, from very early in pregnancy. The unequally shared intrauterine environment contributes to putting each monozygotic twin on a progressively distinct behavioural path.
\end{abstract}

Keywords: monozygotic twins, dizygotic twins, foetal behaviour, twins' intra-pair differences, twins' individual consistencies

\section{Introduction}

Since the publication of Sir Francis Galton's work, ${ }^{1}$ monozygotic $(\mathrm{Mz})$ twins have been studied as a living experiment to try and clarify the nature/ nurture controversy. Although several authors ${ }^{2-6}$ have stressed the importance of considering prenatal factors as important variables in twin studies, only a few retrospective ${ }^{7-10}$ studies and one prospective work $^{11}$ have taken intra-uterine elements into account.

Due to the advent of ultrasounds in obstetrics towards the end of the 1970s, studies of human foetal behaviour have begun to emerge from the mist of anecdotal or largely unverifiable evidence. Prenatal investigations of foetal behaviour are generally difficult to apply to large populations. They also suffer from other limitations, such as the impossibility of obtaining a three-dimensional view of the foetal body and its complete visualisation after the 20th to 22nd week of pregnancy. Nevertheless, fundamental knowledge of behavioural development in utero has been accumulated, paving the way for further methodologically robust explorations. ${ }^{12-16}$

Until fairly recently, prenatal determination of zygosity was only possible in the case of opposite sex (OS) dizygotic (Dz) twin pregnancies. Dz twins al ways have separate placentas and amniotic sacs.

Correspondence: Alessandra Piontelli, Largo Richini 1, 20122 Milano, Italy. Tel/Fax: 0258307193; E-mail: apiontel@micronet.it

Received 14 October 1998; revised 16 June 1999; accepted 24 September 1999
Recent ultrasonograph diagnostic advances have made it possible to establish monozygosity in utero in those cases where the placentas are monochorionic (MC). ${ }^{17-20} \mathrm{Mz}$ twins share $100 \%$ of their nuclear genes, but can have different types of placentation according to when the split initiating the twinning phenomenon takes place. The majority of them $(70 \%)$ share the same placenta and inhabit two different amniotic sacs and are hence called monochorionic (MC), di-amniotic (DA), ${ }^{21,22}$ This prenatal distinction has opened up the possibility of comparing the behaviour of $\mathrm{Mz}$ and $\mathrm{Dz}$ twins in utero. Neverthel ess monochorionicity, and therefore monozygosity, must always be re-confirmed at birth. ${ }^{23}$

In the present work we decided to focus on the early stages of twin pregnancies subdividing our sample according to zygosity in order to 1) evaluate differences in the behaviour of foetal twin pairs; and 2) compare differences and/or similarities in the behaviour of $\mathrm{Mz}$ and $\mathrm{Dz}$ twin pairs.

\section{Subjects and methods}

The hospital ethics committee approved this study and informed consent was obtained from all women taking part.

Fifteen MC-Mz and 15OS-Dz twin pairs were observed by ultrasound weekly from week 10/11 to week 13 gestational age. Subsequent recordings took place between 15/16, 18/19 and 21/22 weeks. Gestational age was calculated from the first day of the last 
menstrual period and confirmed by ultrasound scan. Chorionicity was confirmed at birth by a pathologist in all pregnancies. The cohort of Mz-MC twins comprised $8 \mathrm{male}$ and $7 \mathrm{female}$ pairs. Overall 31 males and 29 femal es were observed.

Mean gestational age at delivery was 36.1 weeks (range $=33-37$ ). Although some children (8) had to have a rather lengthy stay in the intensive care unit (range $=15$ days -1 month), due to their prematurity and to various problems linked with it, all were found to be well at discharge from hospital and at 6 months follow-up.

All ultrasound observations were performed using a $5 \mathrm{MHz}$ probe (Acuson, Mountain View, Ca, USA) and recorded on videotape. At gestational ages $11 / 13$, given the possibility of visualising both foetal bodies simultaneously, the observations lasted $30 \mathrm{~min}$ each. Subsequently, due to the complex spatial distribution of the two foetal bodies, each foetus was observed for 30 consecutive mins, after which the probe was moved to visualise the other twin. The use of two different probes and, moreover,

\section{Pair N.2 - Monozygotic Twins - Linear Regression}

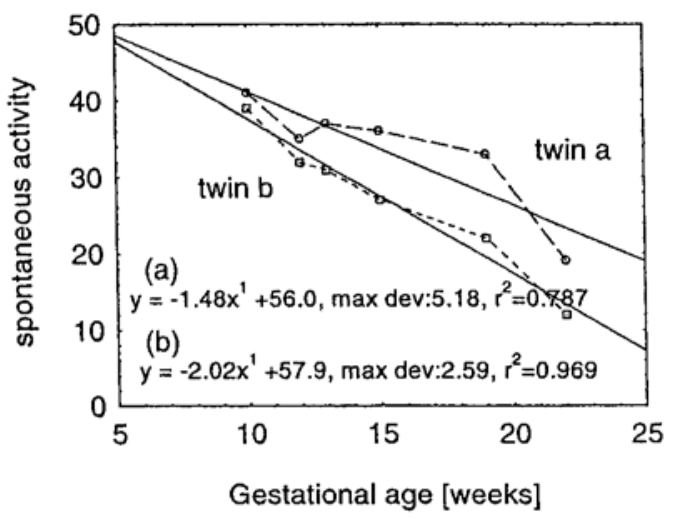

Pair N.6 - Monozygotic Twins - Linear Regression

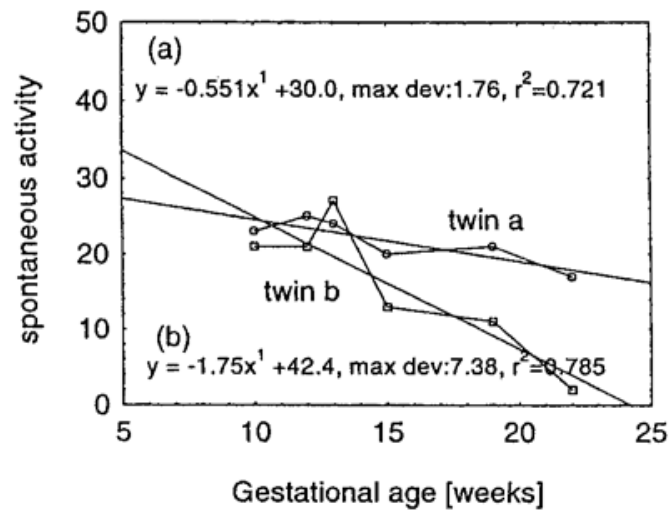

Figure 1 Simple activity plots of Mz pairs of additional probes proved to be unfeasible as the probes were found to interfere with each other. Care was taken al ways to include parts of the co-twin in the ultrasonic field. On each occasion, ultrasonographic foetal measurements, evaluation of amniotic fluid volume, and Doppler blood flow velocimetry were al so obtained. Individual twins were identified at subsequent observations using a combination of criteria, which included foetal gender, placental site, size, and laterality within the uterine cavity.

Foetal motility was analysed retrospectively and independently by two operators through repeated playbacks of the tapes.

All recordings were submitted to four types of analysis:

1) The overall activity level of each foetus during each observation was determined by adding the duration of all spontaneous movements, and was expressed as a percentage of the observation time, hiccups and foetal breathing not being considered active somatic movements.

Pair N.3 - Monozygotic Twins - Linear Regression

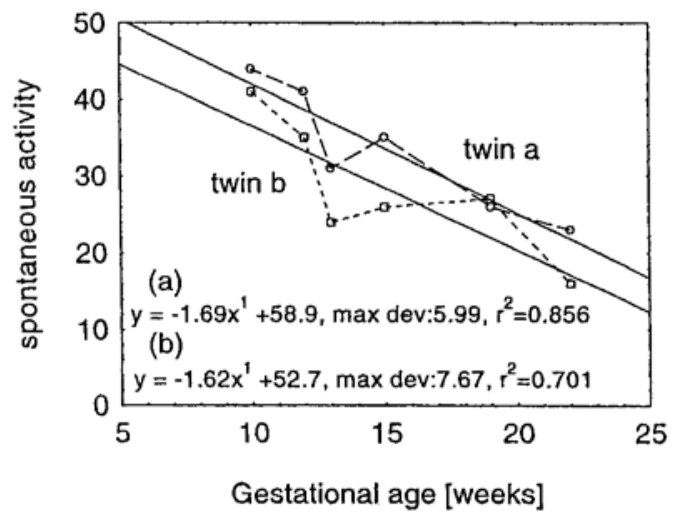

Pair N.11 - Monozygotic Twins - Linear Regression

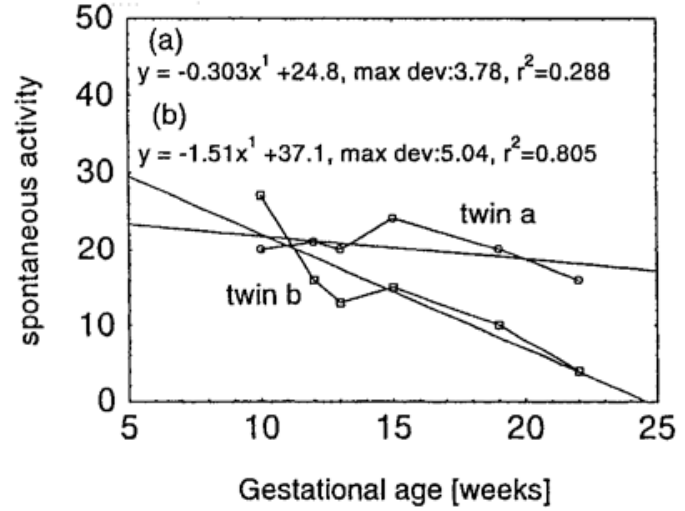


2) Reactivity levels were calculated by adding the duration of all evoked movements. This subdivision, however, was only possible from 13 weeks gestational age, as evoked movements tend to appear later in dichorionic (DC) pregnancies, ${ }^{25}$ thus rendering in this respect the comparison between $\mathrm{Mz}$ and $\mathrm{Dz}$ twins unfeasible at earlier gestational ages.

3) Spontaneous and evoked foetal movement patterns were classified according to de Vries et $\mathrm{al}^{13}$ and counted in seconds in order to investigate the rank order of incidence of the different movement patterns for each individual foetus. This analysis was applied from 15 weeks gestational age, when the motor repertoire of the human foetus can be considered complete. $^{12}$

4) Finally a statistical analysis of the overall spontaneous and evoked activity in relation to time (gestational age) was made. Individual spontaneous and evoked activity levels were analysed with a linear regression. ${ }^{26}$ The behav-

Pair N.1 - Dizygotic Twins -Linear Regression

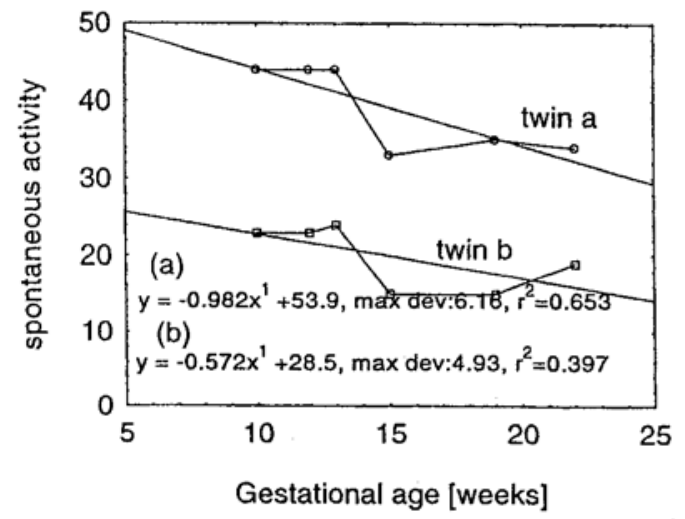

Pair N.9 - Dizygotic Twins - Linear Regression

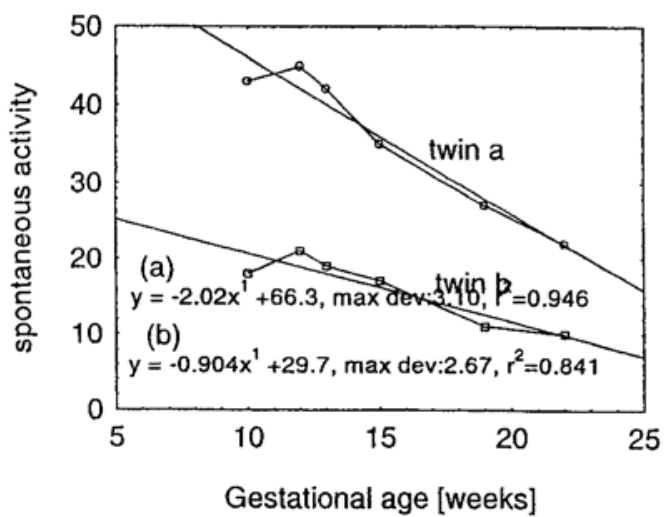

Figure2 Simple activity plots of Dz pairs ioural patterns of all twins were thus described in a simple linear way. These were then checked with the determination coefficient $r^{2}$. An $r^{2}$ value of 0.8 implies that $80 \%$ of the variability can be accounted for by a systematic linear effect attributable to gestational age. ${ }^{26}$

\section{Results}

Inter-pair differences of activity level were found to be consistent over time. The twin in each pair who was relatively more active at one time of observation continued to be more active during other observations.Figures 1 and 2 show some examples of simple activity plots of $\mathrm{Mz}$ and $\mathrm{Dz}$ pairs. Only one pair of Mz twins (Pair 11) deviated from the general pattern. Because of a growing disproportion in the volume of amniotic fluid in the two sacs, the range of motions of the originally more active twin was progressively restricted, so that this twin became the less active.

Pair N.8 - Dizygotic Twins - Linear Regression

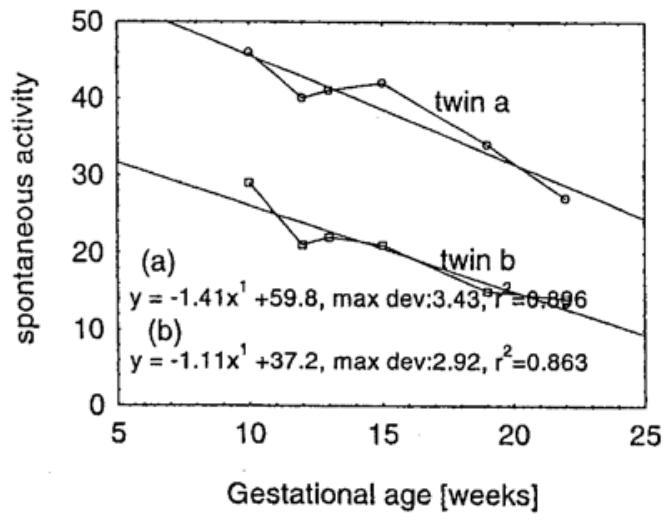

Pair N.15 - Dizygotic Twins - Linear Regression

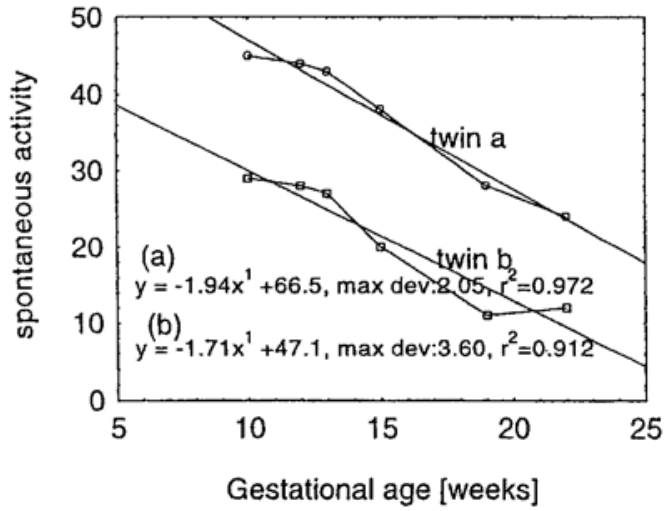


The majority (16 out of 30 cases) of more active twins were found to have greater birth weights compared with their co-twins. This did not apply to higher reactivity levels that were equally distributed amongst lighter and heavier twins (Table 1).

Evoked movements showed an opposite trend compared with activity levels. In $10 \mathrm{Mz}$ and $10 \mathrm{Dz}$ pairs the more active twin was found to be the less reactive. Figures 3 and 4 show some examples of simple reactivity plots of $\mathrm{Mz}$ and $\mathrm{Dz}$ pairs.

Although similarities in activity levels were greater in $\mathrm{Mz}$ than in $\mathrm{Dz}$ twin pairs, activity levels al so differed significantly between $\mathrm{Mz}$ twin pairs.

The within-pair differences of activity levels in Mz twins increased progressively with gestational age, whereas slight trends in the opposite direction were noted in Dz twin pairs.

By 13 weeks gestational age, all twins save two reacted with elicited motions to the physical contact provided by spontaneous movements of the other twin. Within-pair differences of reactive motility were more marked in Dz than in Mz twins, but in $\mathrm{Mz}$ twins the within-pair differences of reactivity increased with age.

As said before, evoked activity starts earlier in MC-Mz twins. ${ }^{25}$ Spatial contiguity and thinner dividing membrane favour earlier stimulation. In our sample evoked activity was considered from 15 weeks gestational age. A previous study had shown this to be the age when most twins, regardless of their chorionicity, start intra-pair stimulation. ${ }^{25}$ Evoked activity displayed a tendency to become homogeneous between $\mathrm{Mz}$ and $\mathrm{Dz}$ twins with increasing gestational age.

Spontaneous activity showed a different trend. Up to 15 weeks gestational age $\mathrm{Mz}$ and $\mathrm{Dz}$ twins showed almost the same trends in activity. After this stage activity diminished in both groups, but more notably in the case of $\mathrm{Mz}$ twins. Figure 5 summarises the overall activity and reactivity trends in relation to gestational age in $\mathrm{Mz}$ and $\mathrm{Dz}$ twins.

Finally the analysis of spontaneous single motor patterns did not reveal greater similarities in the behaviour of $\mathrm{Mz}$ twins. From 15 weeks gestational age $\mathrm{Mz}$ and $\mathrm{Dz}$ twins merged together at a less macroscopic level of investigation showing intertwin differences which persisted over time. Single motor patterns analysed following the classification of De Vries et al, ${ }^{13}$ differed between each pair at all gestational ages. Figures 6 and 7 show some examples of 'actograms' of spontaneous and evoked activity patterns in $\mathrm{Mz}$ and $\mathrm{Dz}$ twins.

Table 1 Sex $r^{2}$ (activity), $r^{2}$ (reactivity) and birth weights of $M z$ and $D z$ twins

\begin{tabular}{|c|c|c|c|c|c|c|c|c|c|}
\hline Mz twins & Sex & $r^{2}$ (activity) & $\mathrm{r}^{2}$ (reactivity) & Birth wt, g & Dz twins & Sex & $\mathrm{r}^{2}$ (activity) & $r^{2}$ (reactivity) & $\overline{\text { Birth wt, } g}$ \\
\hline 1 Twin a & $\mathrm{F}$ & 0.95 & 0.495 & 2.600 & 1 Twin a & M & 0.653 & 0.014 & 2.550 \\
\hline 1 Twin $b$ & $\mathrm{~F}$ & 0.95 & 0.663 & 1.890 & 1 Twin b & $\mathrm{F}$ & 0.397 & 0.3 & 3.100 \\
\hline 2 Twin a & $M$ & 0.787 & 0.938 & 2.350 & 2 Twin a & $\mathrm{F}$ & 0.959 & 0.592 & 1.900 \\
\hline 2 Twin b & $\mathrm{M}$ & 0.969 & 0.192 & 2.840 & 2 Twin b & M & 0.908 & 0.596 & 1.850 \\
\hline 3 Twin a & $\mathrm{M}$ & 0.856 & 0.736 & 2.420 & 3 Twin a & $M$ & 0.858 & 0.672 & 2.260 \\
\hline 3 Twin b & $\mathrm{M}$ & 0.701 & 0.965 & 2.230 & 3 Twin b & $\mathrm{F}$ & 0.82 & 0.774 & 2.290 \\
\hline 4 Twin a & $\mathrm{M}$ & 0.861 & 0.938 & 1.300 & 4 Twin a & $\mathrm{F}$ & 0.773 & 0.218 & 2.340 \\
\hline 4 Twin b & $M$ & 0.754 & 0.4 & 2.200 & 4 Twin b & $M$ & 0.702 & 0.376 & 2.690 \\
\hline 5 Twin a & $\mathrm{M}$ & 0.61 & 0.779 & 2.450 & 5 Twin a & $\mathrm{M}$ & 0.777 & 0.948 & 2.200 \\
\hline 5 Twin b & $\mathrm{M}$ & 0.808 & 0.192 & 2.780 & 5 Twin b & $\mathrm{F}$ & 0.628 & 0.889 & 2.500 \\
\hline 6 Twin a & $\mathrm{M}$ & 0.721 & 0.979 & 2.260 & 6 Twin a & $\mathrm{F}$ & 0.798 & 0.876 & 1.620 \\
\hline 6 Twin b & $\mathrm{M}$ & 0.785 & 0.876 & 2.010 & 6 Twin b & $M$ & 0.425 & 0.801 & 1.890 \\
\hline 7 Twin a & $\mathrm{F}$ & 0.786 & 0.563 & 2.850 & 7 Twin a & $\mathrm{M}$ & 0.777 & 0.411 & 2.760 \\
\hline 7 Twin b & $\mathrm{F}$ & 0.892 & 0 & 2.340 & 7 Twin b & $\mathrm{F}$ & 0.826 & 0.581 & 2.790 \\
\hline 8 Twin a & $\mathrm{F}$ & 0.565 & 0.988 & 2.570 & 8 Twin a & $\mathrm{F}$ & 0.896 & 0 & 3.100 \\
\hline 8 Twin b & $\mathrm{F}$ & 0.775 & 0.793 & 2.500 & 8 Twin b & $M$ & 0.863 & 0.386 & 2.640 \\
\hline 9 Twin a & $\mathrm{M}$ & 0.563 & 0.59 & 1.880 & 9 Twin a & $\mathrm{M}$ & 0.946 & 0.729 & 3.200 \\
\hline 9 Twin b & $\mathrm{M}$ & 0.88 & 0.098 & 2.390 & 9 Twin b & $\mathrm{F}$ & 0.841 & 0.738 & 3.040 \\
\hline 10 Twin a & $\mathrm{F}$ & 0.781 & 0.941 & 2.400 & 10 Twin a & $\mathrm{F}$ & 0.917 & 0.455 & 2.900 \\
\hline 10 Twin b & $\mathrm{F}$ & 0.882 & 0.3 & 2.300 & 10 Twin b & $M$ & 0.871 & 0.963 & 2.330 \\
\hline 11 Twin a & $\mathrm{M}$ & 0.288 & 0.08 & 2.000 & 11 Twin a & M & 0.869 & 0.763 & 1.860 \\
\hline 11 Twin b & $\mathrm{M}$ & 0.805 & 0.505 & 2.560 & 11 Twin b & $\mathrm{F}$ & 0.815 & 0.873 & 2.460 \\
\hline 12 Twin a & $\mathrm{M}$ & 0.87 & 0.69 & 2.300 & 12 Twin a & $\mathrm{F}$ & 0.601 & 0.94 & 2.900 \\
\hline 12 Twin b & $\mathrm{M}$ & 0.815 & 0.588 & 1.800 & 12 Twin b & $M$ & 0.549 & 0.932 & 2.710 \\
\hline 13 Twin a & $\mathrm{F}$ & 0.758 & 0.164 & 1.480 & 13 Twin a & M & 0.874 & 0.138 & 2.820 \\
\hline 13 Twin b & $\mathrm{F}$ & 0.914 & 0.216 & 1.650 & 13 Twin b & $\mathrm{F}$ & 0.886 & 0.763 & 2.900 \\
\hline 14 Twin a & $\mathrm{F}$ & 0.815 & 0.992 & 1.790 & 14 Twin a & $\mathrm{F}$ & 0.745 & 0.009 & 2.800 \\
\hline 14 Twin b & $\mathrm{F}$ & 0.932 & 0.98 & 1.940 & 14 Twin b & $M$ & 0.401 & 0.012 & 1.790 \\
\hline 15 Twin a & $\mathrm{F}$ & 0.944 & 0.992 & 2.140 & 15 Twin a & $\mathrm{F}$ & 0.972 & 0.263 & 1.855 \\
\hline 15 Twin b & $\mathrm{F}$ & 0.976 & 0.1 & 2.750 & 15 Twin b & $M$ & 0.912 & 0.084 & 2.720 \\
\hline
\end{tabular}


Pair N.3 - Monozygotic Twins - Linear Regression

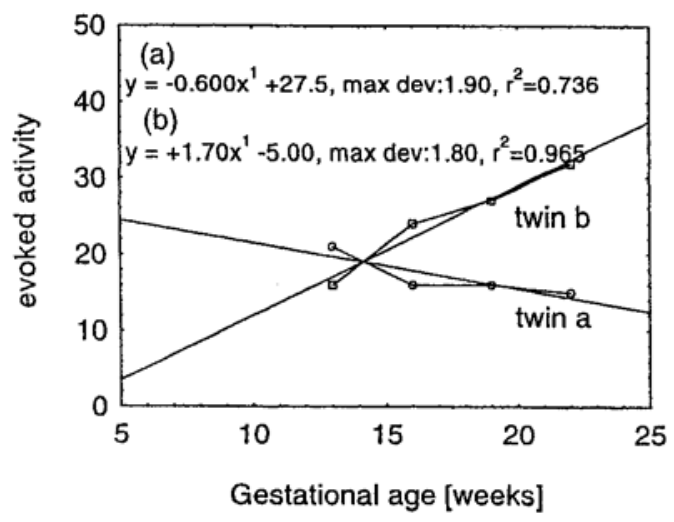

Pair N.12 - Monozygotic Twins - Linear Regression

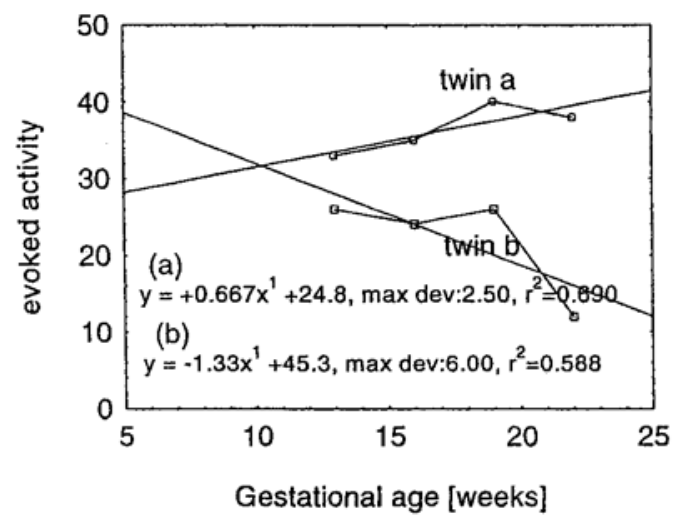

Figure3 Simple reactivity plots of $\mathrm{Mz}$ pairs

\section{Discussion}

Our data would seem to indicate an al ready complex interplay between genetic and environmental forces from the early stages of pregnancy. Active foetal movements begin around 7.5 weeks gestational age. ${ }^{14}$ By 10 weeks gestational age, and possibly before, Mz twins showed difference and consistency of spontaneous and reactive behaviour and this continued over time.

In addition our data would seem to indicate that 'dominance' of one twin may be present in utero. Nevertheless dominance should only be considered to mean that one twin tends to be more active than its co-twin. Activity in the foetus, and particularly so in the first and second trimester, does not mean wakefulness and therefore it cannot entail all the genuinely socially complex interchanges which can only take place in life after birth. The case of the $\mathrm{Mz}$ twin which became constrained in its movements due to an intervening scarcity of amniotic fluid reminds us that initial trends are not unchanging.
Pair N.8 - Monozygotic Twins - Linear Regression

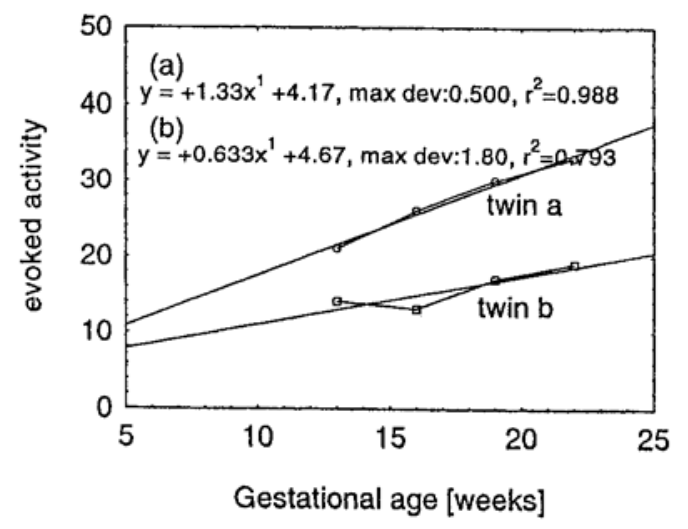

Pair N.13 - Monozygotic Twins - Linear Regression

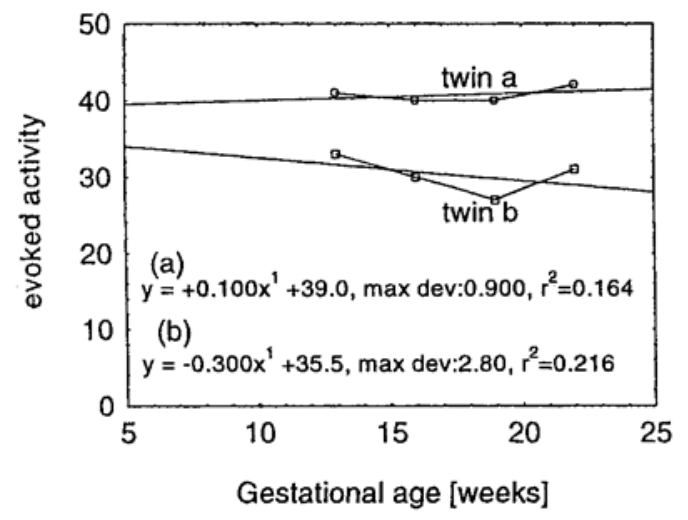

Innumerable variables can always disrupt and change apparently established inclinations.

The inverse relationship found to exist between spontaneous and evoked activity was probably due to the fact that the more active twin was stimulated less often by the less active twin. In addition the fact that similar behavioural patterns were repeated by the same individual at different stages al so seems to substantiate the hypothesis that individual behaviour tends to be well differentiated from early gestational ages.

Although Mz twins initially behaved more similarly than Dz ones, these twins also showed a tendency to differentiate more clearly with advancing gestation. By 22 weeks gestational age their mean differences in activity and reactivity levels almost reached the same degree of magnitude as those of $D z$ twins.

Furthermore the greater similarities shown in the activity and reactivity levels of $\mathrm{Mz}$ twins could not be found when analysing single motor patterns. Individual differences in these were found to be present in both $\mathrm{Mz}$ and $\mathrm{Dz}$ twins. This did not tend 
Pair N.2 - Dizygotic Twins - Linear Regression

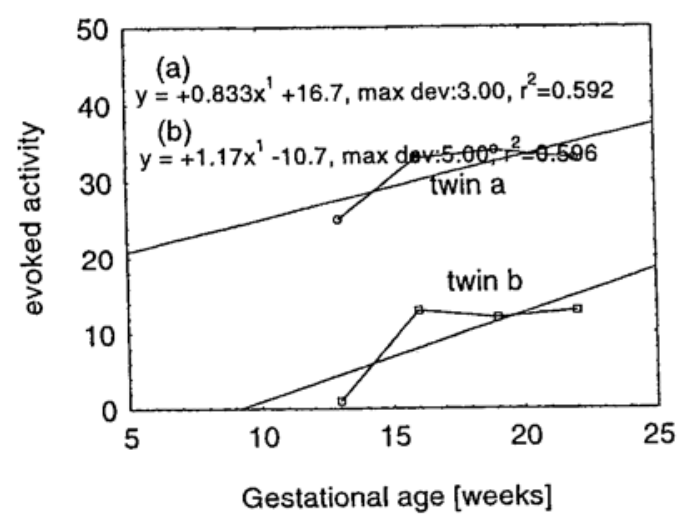

Pair N.8 - Dizygotic Twins - Linear Regression

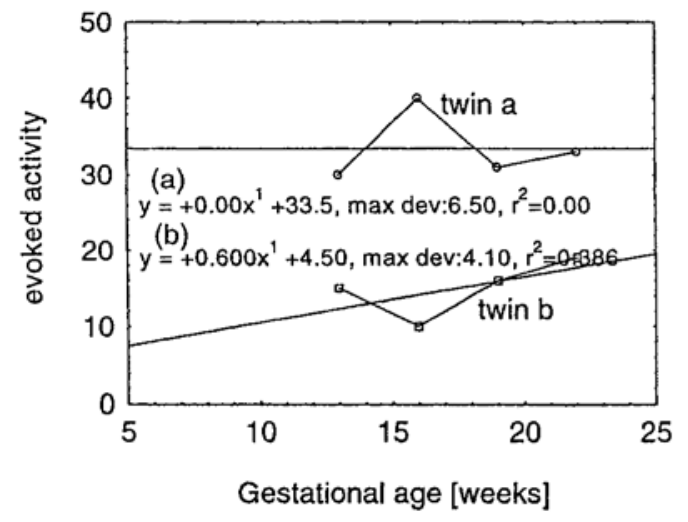

Figure 4 Simple reactivity plots of Dz pairs

Mean Means - Reactivity Levels - Mz and Dz Twins

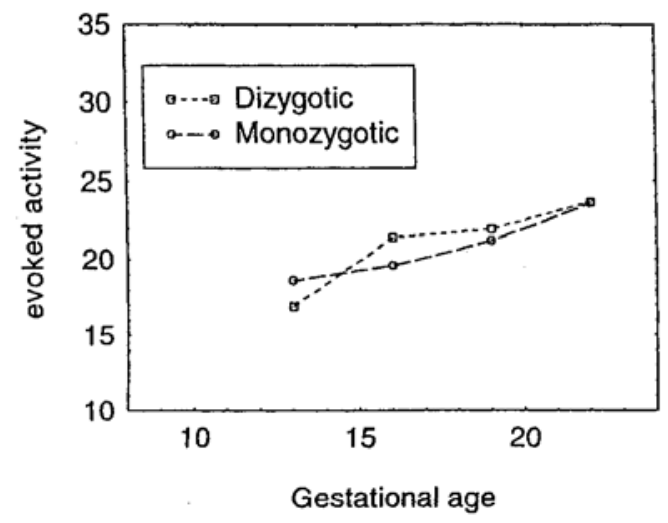

Figure5 Overall trends

to decrease over time, suggesting that each foetus, regardless of its zygosity, had its own individual 'style' of acting and reacting within the broader range of spontaneous behavioural patterns as well as prevalent responses to stimulation.
Pair N.6 - Dizygotic Twins - Linear Regression

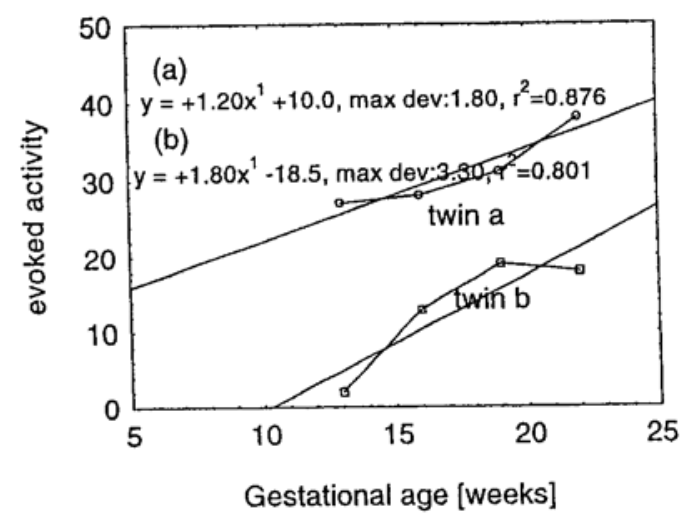

Pair N.10 - Dizygotic Twins - Linear Regression

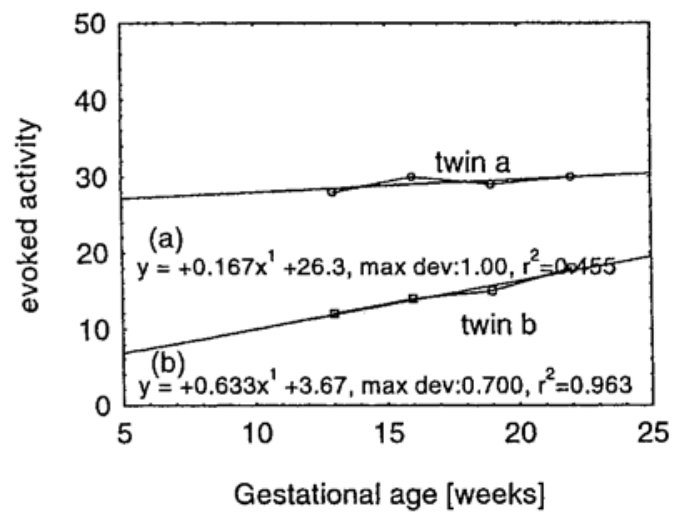

Mean Means - Activity Levels - Mz and Dz Twins

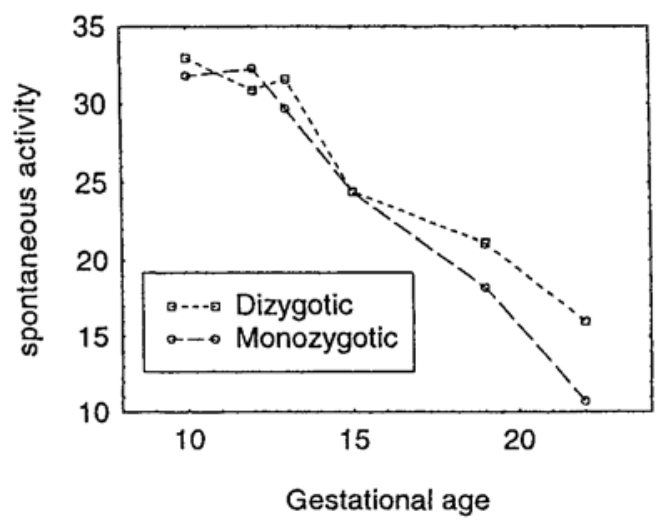

The fact that both $\mathrm{Mz}$ and $\mathrm{Dz}$ twins decreased their activity with advancing gestation was in line with a general decrease in activity in the singleton. ${ }^{27}$ This decrease in activity is global, but affects especially whole body activities such as general movements 


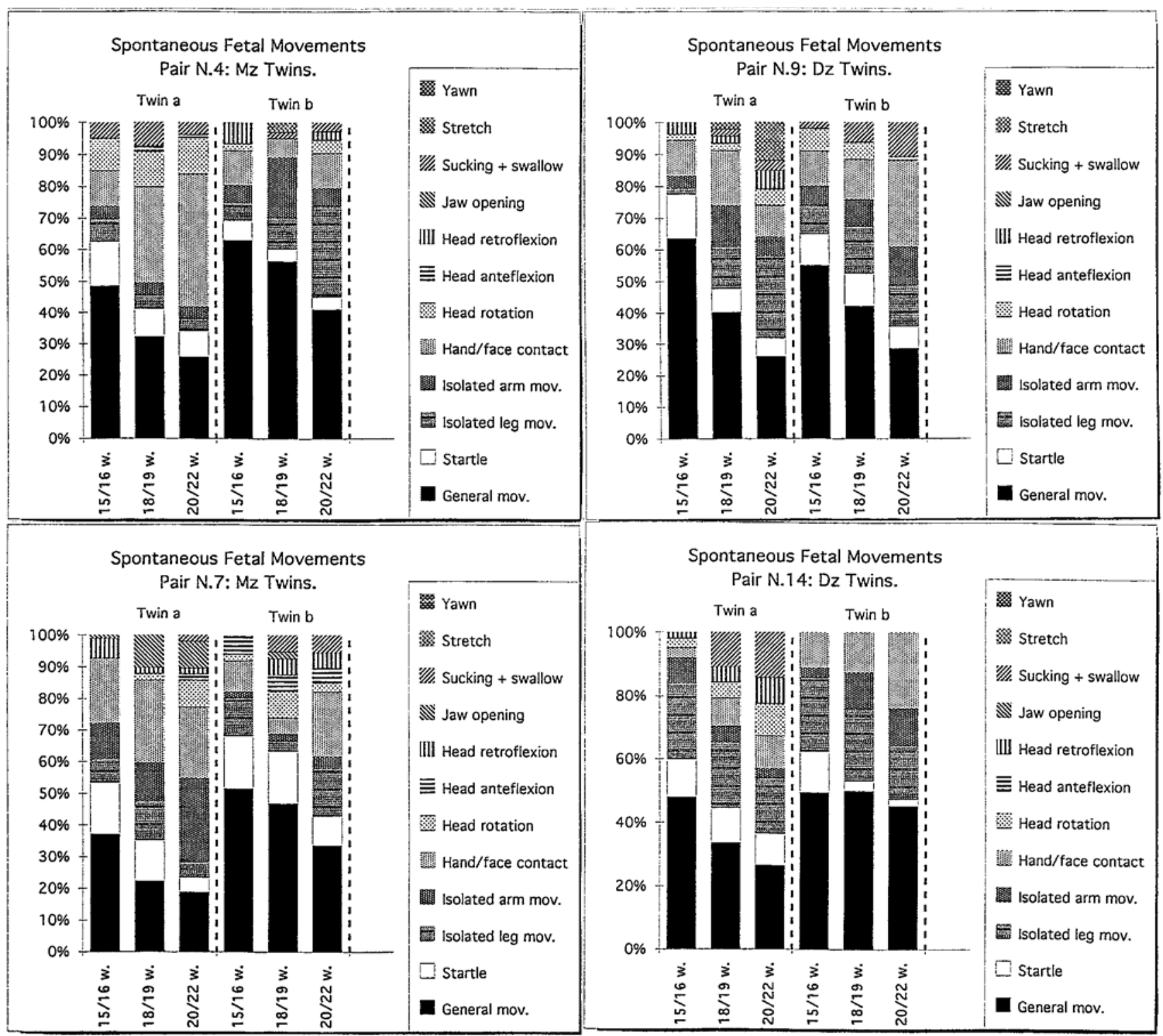

Figure6 Patterns of spontaneous foetal movements ( $\mathrm{Mz}$ and $\mathrm{Dz}$ pairs)

and 'startles'. However, Mz twins decreased their activity more rapidly and sharply. This might possibly be explained by the effects of a more troubled pregnancy making themselves felt earlier in this group. Suffering foetuses tend to spare their energy by moving less. ${ }^{28}$ Intrauterine conditions are generally far from optimal in MC-Mz pregnancies and this could reverbate on the overall activity of $\mathrm{MC}-\mathrm{Mz}$ twin foetuses.

Ideally, one would like to analyse all sub-types of twin pregnancies and be able to compute whether or not sharing the same placenta may add to possible similarities/dissimilarities in Mz twins and whether having the same gender may also increase possible similarities/dissimilarities in Dz twins. We are currently attempting to gather a sufficiently large range of these samples, but this will clearly take a long time. Furthermore, since the majority of $M z$ twins are indeed MC, it may well be that some behavioural characteristics of $\mathrm{Mz}$ twins found in twin studies could be related to this specific type of placentation. Usually twin studies are blind to the type of placentation of twins.

Our combined results would seem to incidate intrauterine environmental factors at play in setting each single foetus in its own behavioural path regardless of its zygosity. The intrauterine environment far from being static is subject to constant 


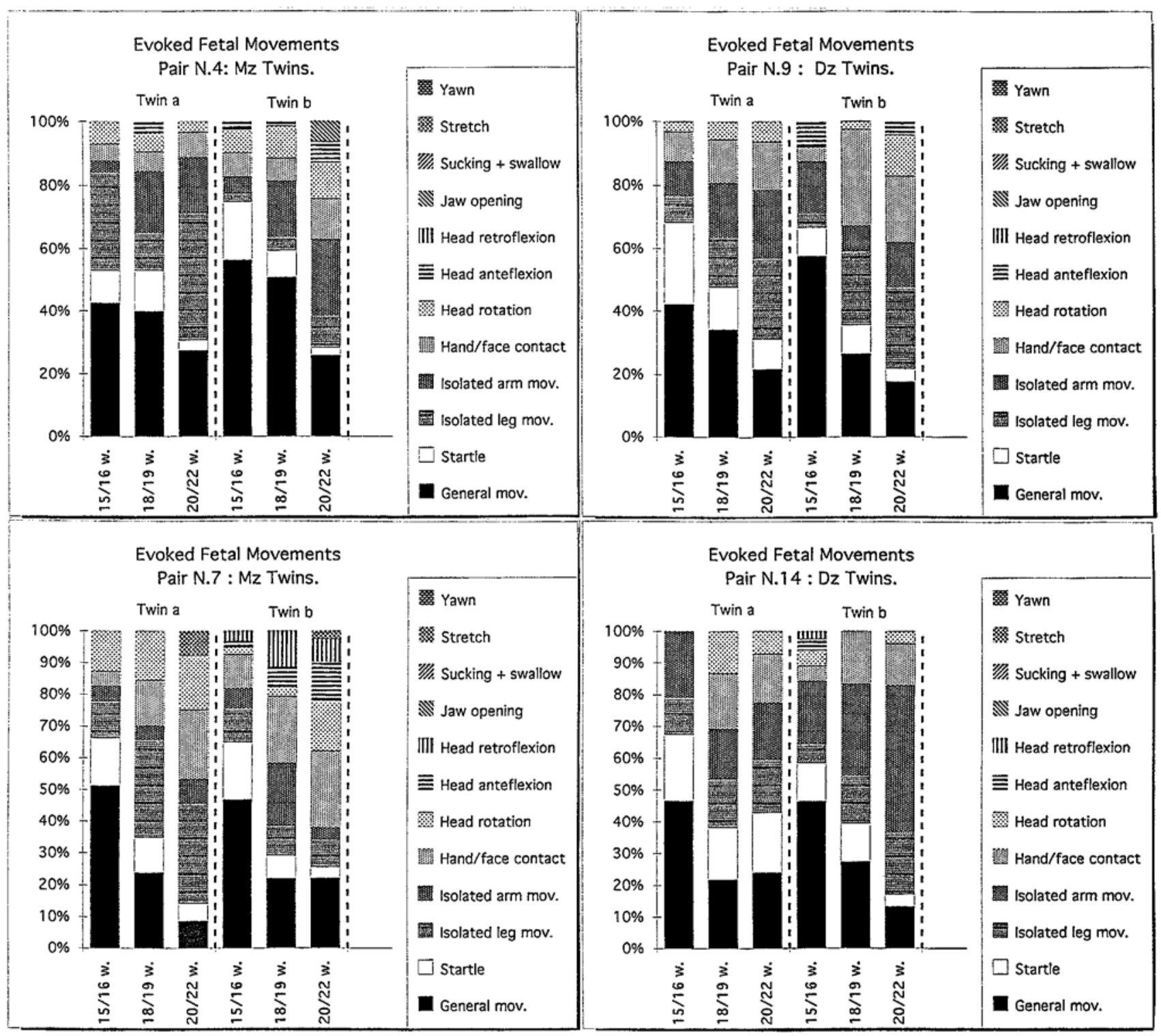

Figure7 Patterns of evoked foetal movements ( $\mathrm{Mz}$ and $\mathrm{Dz}$ pairs)

changes $^{29,30}$ and can show innumerable individual variations even within its main constant components such as the placenta, umbilical cord, and amniotic fluid. ${ }^{31,32}$

This is all the more evident in twin gestations since the majority of twin foetuses do not share such macroscopic components as placentas, umbilical cords and amniotic sacs, but even when they do, their placentas are never equally shared, their amniotic fluid (save in the case of the very rare monoamniotic pregnancies) is never equally distributed and their umbilical cords, even in the extremely uncommon occurrence of a joint insertion, never carry identical blood flows.
Furthermore, twins develop in different locations within the uterus and receive not only an unequal share of blood supply, nutrients and other substances, but also of stimuli. Not only macro but also internal as well as external micro-environmental conditions differ between them from the start. Uniqueness and chance characterise their intrauterine life. Initial differences and apparently small asymmetries in the intrauterine sojourn of identical twins, with all the cascading effects this entails during a particularly turbulent and sensitive stage, may carry great weight ${ }^{33,34}$ in founding so-called constitutional differences and initiating behaviourally divergent paths. 
The frequent weight discrepancy found in twins at birth $^{35}$ is perhaps the most macroscopic result of such unequal and casual partaking. Though none of the twins in our sample suffered from it, Mc twin pregnancies can be subject to a unique dynamic unbalance between their shared placental circulations. This leads to the so-called foetal-foetal transfusion syndrome. ${ }^{36-38}$ This condition can further increase weight and cardiovascular dissimilarities between twins.

In any case, each twin is an integral and active part of the environment of its co-twin. A 'couple effect'39 seems al ready to be operative in life before birth. Nevertheless this should not be taken to mean that twins have complex intra-pair social communications, but simply that intra-pair interactions exist between twin foetuses and that this component is an active and distinctive constituent of the intra-uterine environment.

\section{Acknowledgements}

This work was supported by grants from the ASM Foundation. We wish to thank Professor David Tammaro for statistical elaboration and Mr Martin Anderson for revising our English.

\section{References}

1 Galton F. The history of twins as a criterion of the relative powers of nature and nurture. J Anthro Inst GB Ire 1876; 5: 391-406.

2 Scarr S. Environmental bias in twin studies. Eugen Quart 1975; 15: 34-40.

3 Rutter M. Epidemiological/longitudinal strategies and casual research in child psychiatry. J Am Acad Child Adol Psych 1981; 20: 513-44.

4 Piontelli A. From Fetus to Child, Routledge: London, 1992, pp 234-243.

5 Bryan EM. Prenatal and perinatal influences on twin children: implications for behavioral studies. In: Bouchard TJ, Propping $P$ (eds). Twins as a Tool of Behavioral Genetics. Wiley: Chichester, 1993, pp 217-226.

6 Rutter M, Smirnoff E, Silberg J. How informative are twin studies of child psychopathology? In: Bouchard TJ, Propping P (eds). Twins as a Tool of Behavioral Genetics. Wiley: Chichester, 1993, pp 179-194.

7 Melnick M, Myrianthopoulos NC, Christain JC. The effects of chorion type on variation in IQ in the NCPP twin population. Am JHum Genet 1978; 36: 425-433.

8 Ramos-Arroyo MA, Ulbright TM, Yu PL, Christian JC. Twin study: Relationship between birthweight, zygosity, placentation and pathologic placental changes. Acta Genet Med Gemellol (Roma) 1988; 37: 229-238.

9 Riese ML. Neonatal temperament in monozygotic and dizygotic twin pairs. Child Dev 1990; 61: 1230-1237.

10 Sokol DK, Moore CA, Rose RJ, Williams CJ, Reed T, Christian JC. Intrapair differences in personality and cognitive ability among young monozygotic twins distinguished by chorion type. Behav Genet 1995; 25: 457-465.
11 Arabin B, Gembruch U, van Eyck J. Intrauterine behavior. In: Keith LG, Papiernick E, Keith DM, Luke B (eds). Multiple Pregnancy: Epidemiology, Gestation and Perinatal Outcome. Parthenon Publishing: New York, 1995; pp 331-349.

12 Prechtl HFR. Continuity and change in early neural development. In: Prechtl HFR (ed). Continuity of Neural Functions from Prenatal to Postnatal Life. Blackwell: London, 1984, pp $1-15$.

13 de Vries JP, Visser GHA, Prechtl HFR. The emergence of fetal behavior. I. Qualitative aspects. Early Hum Dev 1982; 7: 301-322.

14 de Vries JP, Visser GHA, Prechtl HFR. The emergence of fetal behavior. II. Quantitative aspects. Early Hum Dev 1985; 12: 99-120.

15 de Vries JP, Visser GHA, Prechtl HFR. The emergence of fetal behavior. III. Individual differences and consistencies. Early Hum Dev 1988; 16: 85-103.

16 Birnholz JC, Stephens JC, Faria M. Fetal movement patterns: a possible means of defining developmental milestones in utero. Am J Roentgenol 1978; 130: 537-540.

17 Barss V, Benacerraf BR, Frigoletto FD. Ultrasonic determination of chorion type in twin gestation. Obstet Gynecol 1985; 66: 779-783.

18 Townsend RR, Simpson GF, Filly RA. Membrane thickness in ultrasound prediction of chorionicity of twin gestation. J Ultrasound Med 1988; 7: 327-332.

19 D'Alton ME, Dudley DK. The ultrasonographic prediction of chorionicity in twin gestation. Am JObstet Gynecol 1989; 160 : 557-561.

20 Sabbagha RE. Pregnancy dating and evaluation by ultrasonography. In: Keith LG, Papiernick E, Keith DM, Luke B (eds). Multiple Pregnancy: Epidemiology, Gestation and Perinatal Outcome. Parthenon Publishing: New York, 1995; pp 215-237.

21 Burn J, Corney G. Zygosity determination and the types of twinning. In: MacGillivray I, Campbell DM, Thompson B (eds). Twinning and Twins. Wiley: Chichester, 1988, pp 7-26.

22 Benirschke K, Kaufmann P. Pathology of the Human Placenta. Springer Verlag: New York, 1995.

23 Fisk NM, Bryan EM. Routine prenatal determination of chorionicity in multiple gestation: a plea to the obstetrician. $\mathrm{Br}$ J Obstet Gynaecol 1993; 100: 975-977.

24 Baldwin VJ. Pathology of Multiple Pregnancy. Springer Verlag: New York, 1994.

25 Piontelli A, Bocconi L, Kustermann A, Tassis B, Zoppini C, Nicolini U. Patterns of evoked behaviour in twin pregnancies during the first 22 weeks of gestation. Early Hum Dev 1997; 50 : 39-46.

26 Armitage P, Berry G. Statistical Methods in Medical Research. Blackwell: Oxford, 1994.

27 Manning FA. Fetal movement and tone. In: Manning FA. Fetal Medicine. Principles and Practice. Appleton and Lange: Norwalk, (CT), 1995, pp 145-172.

28 Manning FA, Platt LD, Sipos L. Antepartum fetal evaluation: Development of a fetal biophysical score. Am JObstet Gynecol 1980; 136: 787-792.

29 Smotherman PW, Robinson RR. The uterus as environment: the ecology of fetal behavior. In: EM Blass (ed). Handbook of Behavioral Neurobiology, Vol 9, Developmental Psychobiology and Behavioral Ecology. Plenum Press: New York, 1988, pp 149-189.

30 Alberts $R$, Cramer CP. Ecology and experience. Sources of means and meaning of developmental change. In: EM Blass (ed). Handbook of Behavioral Neurobiology, Vol 9, Developmental Psychobiology and Behavioral Ecology. Plenum Press: New York, 1988, pp 1-35.

31 Lev R, Orlic D. Protein absorption by the intestine of the fetal rat in utero. Science 1972; 177: 522-524. 
32 Moessinger AC, Blanc WA, Marone PA, Polsen DC. Umbilical cord length as an index of fetal activity: experimental study and clinical implications. Pediat Res 1982; 16: 109-112.

33 Edelmann GM. Neural Darwinism: The Theory of Neuronal Group Selection. Plenum Press: New York, 1987.

34 Thelen E. Dynamical systems and the generation of individual differences. In: Colombo J, Fagen J (eds). Individual Differences in Infancy: Reliability, Stability, Prediction. Lawrence Erlbaum: Hilsdale, (NJ), 1990, pp 19-43.

35 Rausen AR, Seki M, Strauss L. Twin transfusion syndrome. A review of 19 cases studied at one institution. J Pediatr 1965; 66: 613-628.
36 Naeye RL. The fetal and neonatal development of twins. Pediatrics 1964; 33: 546-553.

37 Naeye RL. Organ abnormalities in human parabiotic syndrome. Am J Pathol 1965; 46: 829-842.

38 Tan $\mathrm{KL}$, Tan $\mathrm{R}$, Tan $\mathrm{SH}$. The twin transfusion syndrome. Clinical observations on 35 affected pairs. Clin Pediatr 1979; 18: $111-114$

39 Zazzo R. Les jumeaux, le couple et la personne. PUF: Paris, 1960. 